\title{
Energy Transfer and Distribution Optimization of PTFE with Implanting Metal Ions
}

\author{
Hui Tang \\ School of Material Science and Engineering, \\ Harbin University of Science and Technology, \\ Harbin, China \\ Tanghui60003@sina.com \\ Xuan shao \\ Beijing Aeronautical Science \& Technology \\ Research Institute \\ Commercial Aircraft Corporation of China Ltd \\ Beijing China \\ 1506132912@qq.com
}

\author{
Lei $\mathbf{L i}$ \\ School of Material Science and Engineering, \\ Harbin University of Science and Technology, \\ Harbin, China \\ 1062357164@qq.com \\ Wenxue Wang \\ School of Material Science and Engineering, \\ Harbin University of Science and Technology, \\ Harbin, China \\ 379190169@qq.com
}

\begin{abstract}
- order to explore the effective ways and methods of improving the tribological properties of polytetrafluoroethylene (PTFE), energy transfer were optimized with using the SRIM software. when different kinds of metal ion sources ( $\mathrm{Al}, \mathrm{Gr}, \mathrm{Ni}, \mathrm{Ag})$, implantation energies $(20,25,30,40 \mathrm{KeV})$, and different doses of $\left(1 \times 10^{14} 、 1 \times 10^{15} 、 5 \times 10^{15} 、 1 \times 10^{16}\right.$ ions $\left./ \mathrm{cm}^{3}\right)$ were employed, Stimulation and optimization design in this paper mainly focused on one aspect of the four implanted metal particles: energy transfer. adjust implantation energy in four different values, Research showed, Wear resistance of PTFE is improved better by ion implantation. When four different kinds of ions (Al, $\mathrm{Cr}, \mathrm{Ni}$, and $\mathrm{Ag}$ ) are implanted to PTFE, Al ions show the best implantation effect among the four kinds of metal ions.when implantation energy was $20 \mathrm{KeV}$, it can lead to a best modification effect and can also maintain a sufficient implantation depth and a smaller damage. When implant Al ions with the same implantation energy, the nano-composite film can be more homogeneous and the performance can be more consistent with the increase of the ion dose.
\end{abstract}

Keywords- Ion implantation, Surface modification, Polytetrafluoroethylene, Computer optimization

\section{INTRODUCTION}

PTFE is a kind of engineering material which has incomparable advantages compared with other engineering materials, it can be widely applied in industrial production, but its application can also be limited due to its poor wear resistance ${ }^{[1-6]}$. In order to explore the effective ways and methods of improving the tribological properties of PTFE ${ }^{[7-9]}$, surface microstructure and tribological properties were optimized and designed while considering the surface microstructure of PTFE and the energy distribution when implanted multiple metal ions. For different implantation metal ions, different implantation energy were selected according to calculation results which was got by SRIM software and the ions were implanted with different doses in different depth to the surface of PTFE, then it could fully reflect the distribution state and energy change process of surface composition of modified PTFE. Metal/PTFE nanocomposites were obtained and the wear-resistant was improved with implanting nano-sized multiple metal particles on the basis of ensuring the self-lubricating property of PTFE.

\section{OPTIMAL DESIGN OF EXPERIMENTS}

In this paper, optimization and simulation of metal ion implantation technology were carried out by the SRIM software which could calculate the ion range and energy

${ }^{[10]}$.The software was developed by Dr Ziegler (Yale university)which was a special software in molecular dynamics simulation of elements change in the film growth process and was also a classic program to simulate ion radiation damage on the material and a simulation software to calculate the resistance and distribution range of ions $(10 \mathrm{eV} \sim 2 \mathrm{GeV})$ in a solid. SRIM software mainly simulate transport process of particles in the solid, including the ion distribution, energy distribution of recoil atoms, atomic absorption energy and atomic sputter rate, etc. Ion energy required for SRIM is $10 \mathrm{eV} / \mathrm{amu}$ to 2 $\mathrm{GeV} / \mathrm{amu}$, and the number of layers can up to eight with twelve different elements.

Simulation of implant ions to PTFE was carried out with different metal ion source $\mathrm{s}(\mathrm{Al}, \mathrm{Gr}, \mathrm{Ni}, \mathrm{Ag})$, implantation energies $(20,25,30,40 \mathrm{KeV})$ and different doses of $\left(1 \times 10^{14} 、 1 \times 10^{15} 、 5 \times 10^{15} 、 1 \times 10^{16} \mathrm{ions} / \mathrm{cm}^{3}\right)$.In this paper, the fixed point implantation method was used with the implantation rate of 290-295ions/min. Metal/PTFE nano-composites were obtained with SRIM simulation of implanting particular metal cations to PTFE in the approximate vacuum environment. Implantation of new particles would change the microstructure of PTFE and result in an increase of its mechanical properties. By setting the parameters of environment, the incident ions and target particles, also combined with collision theory, 
we could get the range of incident ions and the particles distribution. we could get the best optimization design program.

This paper has a great signification on the exploratory of developing PTFE wear-resistant materials in industrial production by simulating the effects of implantation depth and dose of different kinds of metal ions on properties of PTFE surface properties, and by studying the modification mechanism.

\section{SiMULATION OF ENERGY TRANSFER AND DISTRIBUTION AND CALCULATION}

In one process of collision, energy was transferred from incident ions to recoil atoms. The ordinates of figure 3-1 to figure 3-3 show energies of recoil atoms were given when single incident ion passed per unit distance (1 angstrom) in different depths. It was statistical average of large numbers of incident ions in different conditions. Though it could not reflect the energy transfers of each ion, required data could be obtained from theses figures when energy transfers of total incident ions were calculated.

\section{A. Energy Transfe rand Distribution When Implanted Different Ions}

Energy transfers when implanted different ions with the same implantation energy $(20 \mathrm{KeV})$ and same dose $\left(1 \times 10^{14}\right.$ ions $\left./ \mathrm{cm}^{3}\right)$ were shown in figure $3-1$.

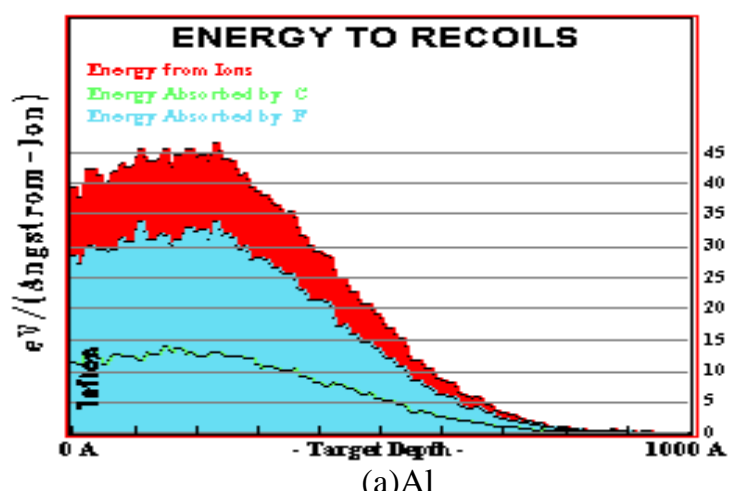

(a)Al

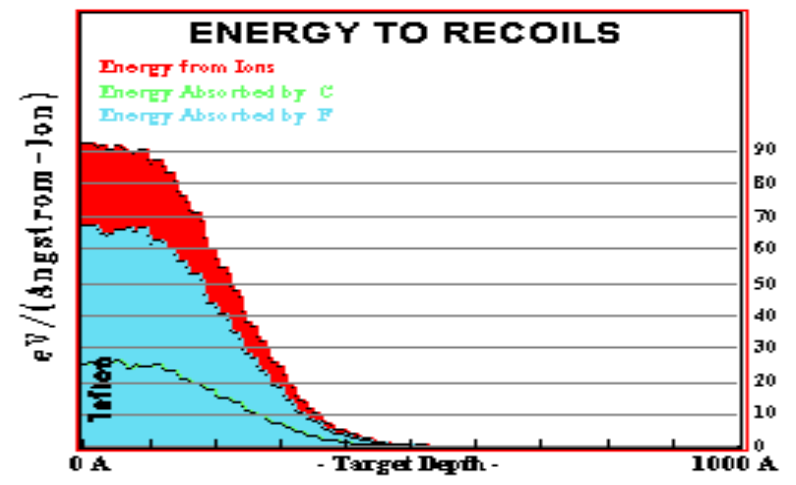

(b) $\mathrm{Cr}$

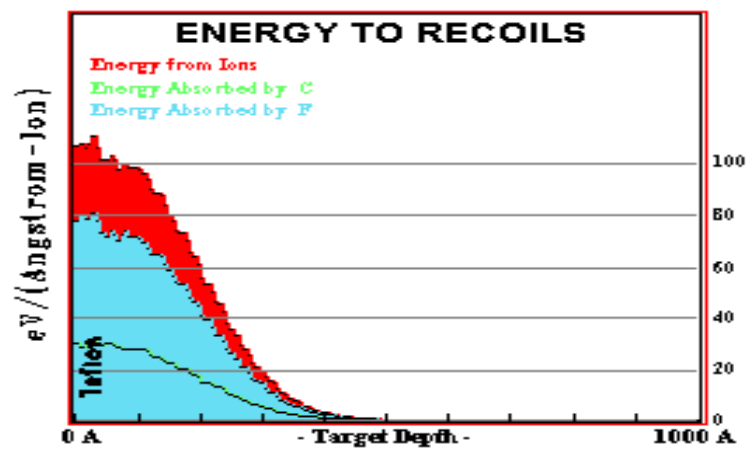

(c) $\mathrm{Ni}$

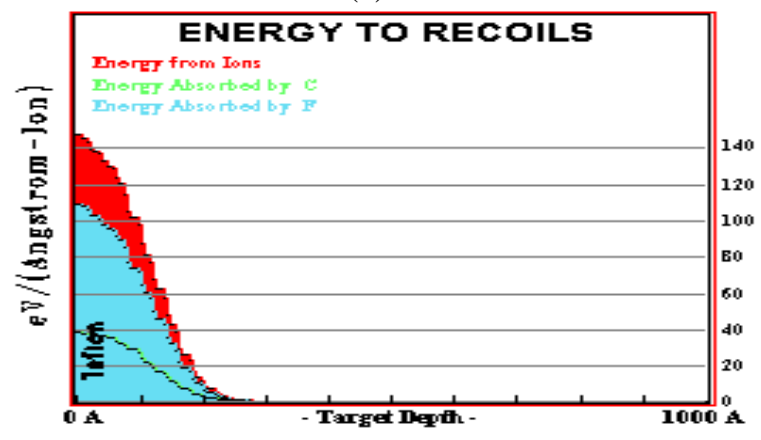

(d)Ag

Figure 3-1 Energy transfer when implanted different ions

In figure 3-1(a), the implantation ion was Al. There was about $45.1 \mathrm{eV}$ energy came out from $\mathrm{Al}$ ions, in which $13.8 \mathrm{eV}$ energy was transferred to carbon atoms and $32.1 \mathrm{eV}$ to fluorine atoms. Implantation of $\mathrm{Cr}$ ions was given in figure 3-1(b). There was about $90.1 \mathrm{eV}$ energy transferred in total, in which $26.8 \mathrm{eV}$ was transferred to carbon atoms and $66.8 \mathrm{eV}$ was absorbed by fluorine atoms. In figure 3-1(c), implantation ion was Ni. There was about $110.1 \mathrm{eV}$ energy transferred in total, in which $31.8 \mathrm{eV}$ was absorbed by carbon atoms and $78.5 \mathrm{eV}$ was absorbed by fluorine atoms. Implantation of $\mathrm{Ag}$ ions was given in figure $3-1(\mathrm{~d})$. There was $142 \mathrm{eV}$ energy transferred in total, and in which $32 \mathrm{eV}$ was absorbed by carbon atoms and $110 \mathrm{eV}$ was absorbed by fluorine atoms.

In PTFE, lattice energy was $3 \mathrm{eV}$, surface bond energy of $\mathrm{C}$ was $7.41 \mathrm{eV}$, surface bond energy of $\mathrm{F}$ was $2 \mathrm{eV}$. Atomic displacement energy of $\mathrm{C}$ was $28 \mathrm{eV}$, atomic displacement energy of $\mathrm{F}$ was $25 \mathrm{eV}$. Nuclear prevent energy of $\mathrm{C}$ was $3.982 \mathrm{eV}$, nuclear prevent energy of $\mathrm{F}$ was $10.981 \mathrm{eV}$. In the process of implantation ions, carbon atoms moved away from original positions and formed displaced atoms until they were irradiated by $\mathrm{Ni}$ and $\mathrm{Ag}$ ions. While fluorine atoms could move longer because of their low displacement energy.

Compared with others in figure 3-1, figure 3-1(a) showed that in the same condition that $F$ atoms could move, more displacement atoms would be left when implanted $\mathrm{Al}$ ions, meanwhile the $\mathrm{C}$ skeleton structure of PTFE was kept, and then it could preserve the ability of forming transfer film when bearing load. 


\section{B. Energy Transfer and Distribution with Different Implantation Energies}

Energy transfer with different implantation energies under the condition of same implantation ion (Al) and same dose $\left(1 \times 10^{14}\right.$ ions $\left./ \mathrm{cm}^{3}\right)$ were shown in figure 3-2. With increasing of implantation depths, energy absorption peaks of matrix atoms could move, but the energy lose of each collision was same.

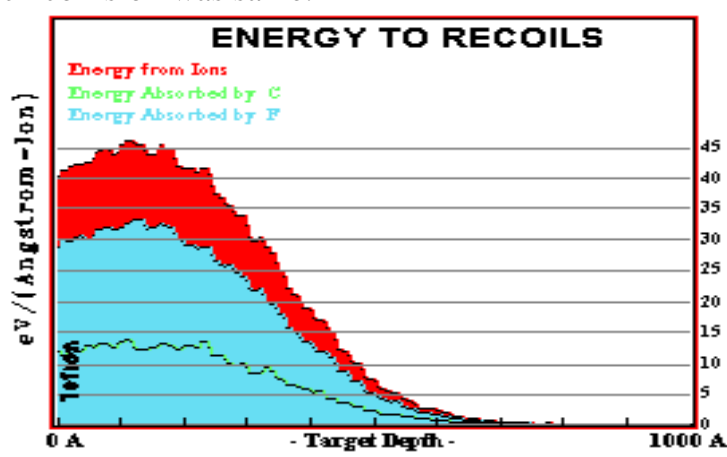

(a) $20 \mathrm{KeV}$
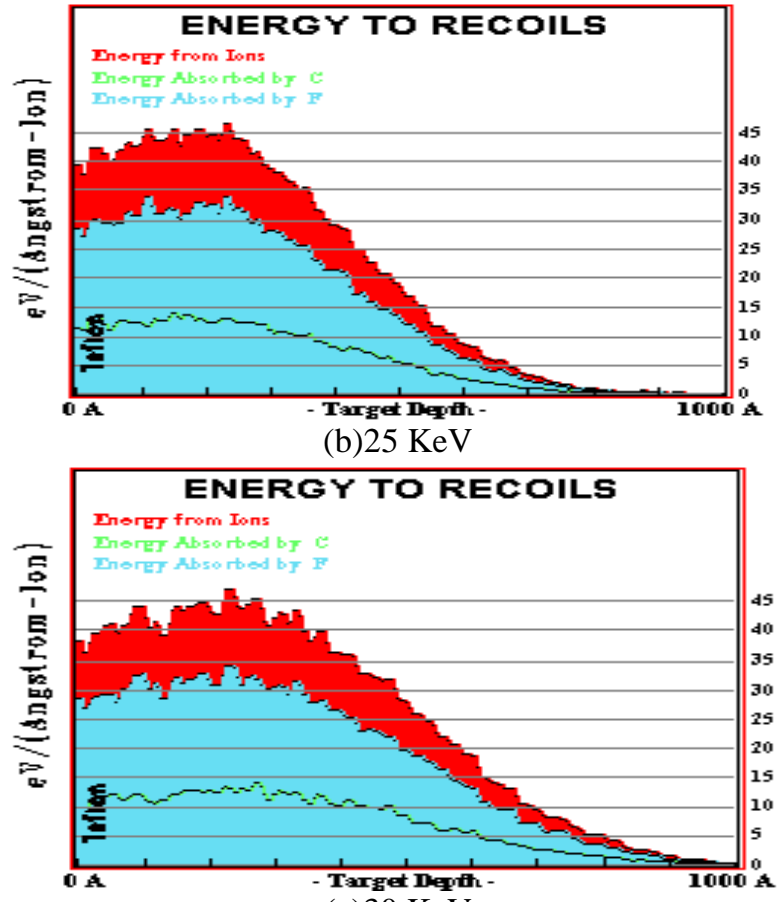

(c) $30 \mathrm{KeV}$

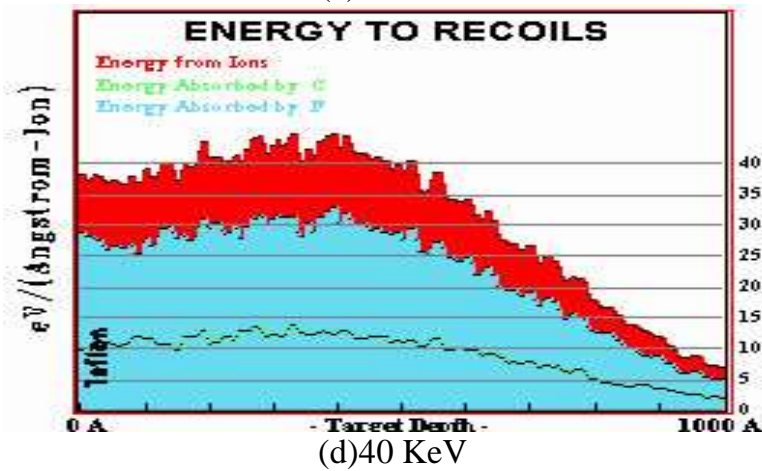

Figure 3-2 Energy transfer with different implantation energies when implanted $\mathrm{Al}$ ions

\section{Energy Transfer and Distribution with Different Implantation Doses}

Figure 3-3 showed that in the condition of the same implantation ions ( $\mathrm{Al})$ and energy $(20 \mathrm{KeV})$, atomic absorption peaks tended to be uniform and the curves could become smoother with the increasing of implantation doses. It indicated that ion implantation was a probabilistic random event and it obeyed the statistical laws. Damages on C skeleton structure of materials were the least when implanted $\mathrm{Al}$ ions, it was benefit to hold the material capacities of forming transfer film and selflubricating.

Effects and parametric variations of implantation of four kinds of ions to PTFE were studied by simulation and optimization of SRIM software. It indicated that when implanting different metal ions to PTFE, damages on lamellar structure of PTFE caused by Al ions were lightest, and it was benefit for keeping self-lubricating properties of materials. In addition, scatting of $\mathrm{Al}$ ions was stronger than others, then it could formed a thicker and more uniform nano-composite film. When bearing load, symmetry of mechanical properties of the transfer film could be well kept and the wear resistance could be improved.

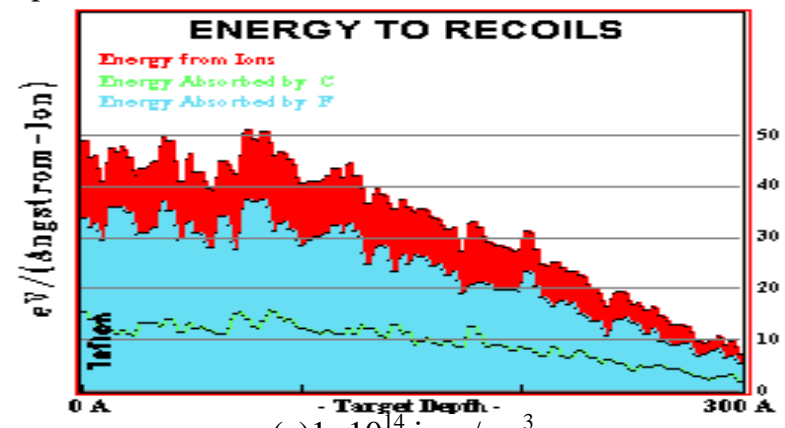

(a) $1 \times 10^{14}$ ions $/ \mathrm{cm}^{3}$

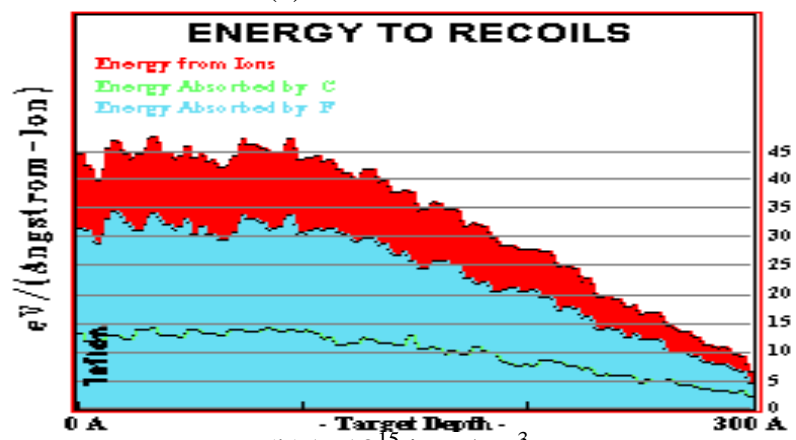

(b) $1 \times 10^{15}$ ions $/ \mathrm{cm}^{3}$

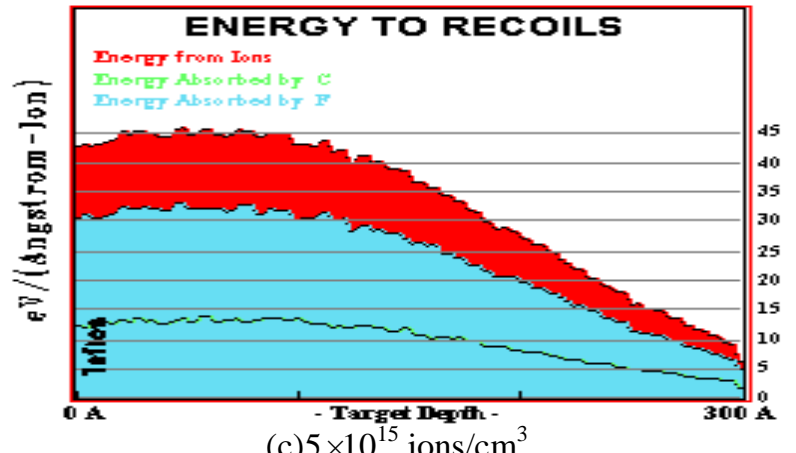

(c) $5 \times 10^{15} \mathrm{ions} / \mathrm{cm}^{3}$ 


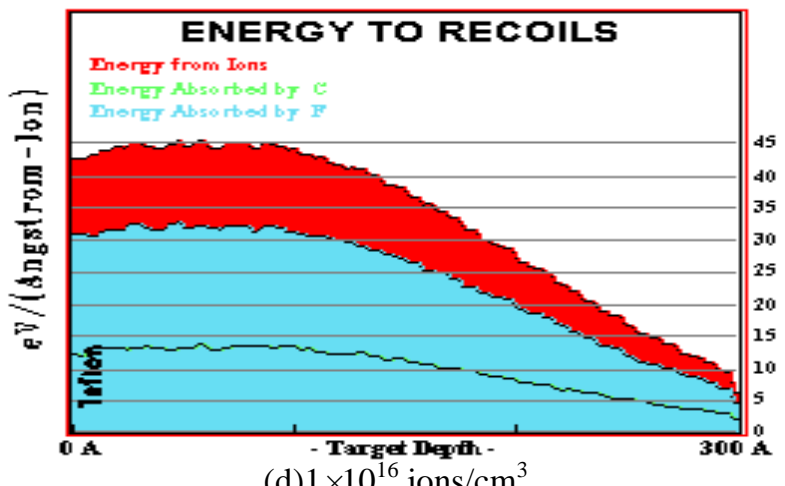

(d) $1 \times 10^{16}$ ions $/ \mathrm{cm}^{3}$

Figure 3-3 Energy transfer of $\mathrm{Al}$ ions with different implantation doses

With the increasing of implantation energy, the nano-composite film became thicker, distribution of doping ions became broader and the distribution peaks of incident metal ions and recoil particles skewed larger, then resulted in a differentiation of the structure of nanocomposite film. With the enhancement of radiation diffusion, number of reset atoms increased, meanwhile aggravated the damage on PTFE. So selecting of implantation energy depends on both of them. Nanocomposite film and its properties would trend to be more uniform with the increasing of implantation dose of metal ions. On the other hand, increasing of implantation dose of metal ions could also lead to an enhancement of the radiation diffusion, and then aggravated the damages on materials. So selecting of implantation dose of metal ions also depended on integration of them.

\section{CONCLUSIONS}

The following conclusions were given by optimization of simulation experiment and analysis.

(1). Wear resistance of PTFE is improved better by ion implantation. When four different kinds of ions ( $\mathrm{Al}$, $\mathrm{Cr}, \mathrm{Ni}$, and $\mathrm{Ag}$ ) are implanted to PTFE, damages on lamellar structure of PTFE by Al ions are the least, and it is benefit for keeping self-lubricating properties of materials. In additions, Al ions show a stronger scatter, meanwhile the formed nano-composite film is thicker and more uniform, when bearing load, symmetry of mechanical properties of transfer film can be well kept, then improve the wear resistance of PTFE. Thus Al ions show the best implantation effect among the four kinds of metal ions.

(2). The best modification effect can be obtained when implanting $\mathrm{Al}$ ions with the implantation dose of
$1 \times 10^{14}$ ions $/ \mathrm{cm}^{3}$, and implantation energy of $20 \mathrm{KeV}$, with different implantation energies.( 20, 25, 30, $40 \mathrm{KeV}$ )

(3).When implanting the $\mathrm{Al}$ ions with the same implantation energy, nano-composite film and its properties are more uniform with the increasing of implantation dose. In addition, increasing of implantation dose can also lead to intense radiation diffusion and then aggravate the damage on PTFE. So, selecting of implantation dose depends on uniformity of the modified nano-composite film and quantity and range of the damages. In this paper, modification of PTFE shows the best effect when implantation dose is $1 \times 10^{16}$ ions $/ \mathrm{cm}^{3}$.

\section{ACKNOWLEDGMENT}

This work was supported in part by NSF Heilongjiang Province of China under Grant Nos.E201130.

\section{REFERENCES}

[1]. Jiang Xufeng, Ji Feng, Sun Shian. Research on Tribology Characteristic and Modification of PTFE Lubricating Materials[J]. Friction Sealing Material, 2006, 4(3): 168-173.

[2]. Xie Gang, Huang Chengya. Research on Modification Technology of Polytetrafluoroethylene[J]. Synthetic Materials Aging and Application, 2007, 36(1): 23-25.

[3]. Yuan Haigen, Zeng Jinfang, Yang Jie. Progress in Research on Modification of PTFE[J]. China Plastics Industry, 2005, 33(8): 7 9.

[4]. Wang Zhichao, Kou Kaichang, Zhao Qingxin. Research Progress of Surface Modification of PTFE[J]. China Adhesives, 2009, 18(9): 47-51.

[5]. Gao Weili. Modification of Surface Tribology Characteristic of PTFE[J]. The Chinese Journal of Nonferrous Metals, 2008, 18(6): 1130-1134.

[6]. Man Baoyuan, Zhang Yunhai, Lü Guohua. Study on Surface Modification of Polytetrafluoroethylene by $\mathrm{N}^{+}$Ion Implantation[J]. Acta Physica Sinica, 2005, 54(2): 838-841.

[7]. QIAO Q, JI J J, ZHANG C G, et al. . Investigation on Aluminum Back Surface Fields Prepared with Vacuum Evaporate [J]. Acta Energiae Solaris Sinica, 2008, 29(5): 555-559.

[8]. FAN D W. The development status and trends of Green coating technology[J]. Information of Surface Engineering, 2008, (5): 3-4.

[9]. Environment department of National Development and Reform Committee. Accelerate extensive the green coating technology and advance pollution emission reduction for Electroplating industry[J]. China Economic \& Trade Herald, 2008, (16): 8-9.

[10]. Tan Moqiang. SRIM ASIPP[M]. Beijing: China Machine Press, 2005: 6-21. 